\title{
RESEÑA DEL LIBRO HEGEMONÍA Y DEMOCRACIA EN DISPUTA. TRUMP Y LA GEOPOLÍTICA DEL NEOCONSERVADURISMO, DE MARCO A. GANDÁSEGUI Y JAIME ANTONIO PRECIADO CORONADO (COORDINADORES) $(2017)^{1}$
}

José Javier Capera Figueroa²

caperafigueroa@gmail.com

Universidad Autónoma del Estado de México

La incertidumbre de nuestros tiempos nos obliga a pensar la realidad desde una perspectiva crítica y propositiva. La importancia de ver a contrapelo la dinámica de una sociedad globalizada, bajo los intereses del capital privado y la lógica del proyecto neoliberal, se convierte en una invitación a reflexionar sobre la capacidad del sujeto, las comunidades, los movimientos sociales, los grupos populares y los actores colectivos; de dar un giro en el campo de la subalternidad y la resistencia con respecto a la crisis civilizatoria del siglo XXI.

La situación en materia de política internacional, a partir de las elecciones de Estados Unidos y el triunfo estratégico de Donald Trump, ha generado una serie de análisis sobre el papel de los colectivos, las organizaciones y los movimientos encargados de dinamizar la democracia en América Latina, África, Asia y Europa, en particular los sectores periféricos, que se encuentran enfocados en generar una disputa frente a la estructura moderno/colonial del sistema mundo capitalista.

Así pues, la importancia de este libro radica en la capacidad de poner en discusión, desde la geopolítica crítica de Nuestra América, la reconfiguración

1 Publicado en México por la Universidad de Guadalajara. Centro Universitario de Ciencias Sociales y Humanidades, 349 p. ISBN: 978-84-17290-14-6

2 Politólogo de la Universidad del Tolima. Maestro en sociología política del Instituto de Investigaciones Dr. José María Luis Mora y estudiante del Doctorado en Ciencias Sociales y Políticas de la Universidad Iberoamericana (México). Analista político y columnista del periódico El Nuevo Día (Colombia) y Rebelión. org (España). Blog: http://josecaperafigueroa.blogspot.mx/ 
de una lógica a partir de las elecciones de Estados Unidos y cómo dicha situación se convertiría en un campo emergente para la investigación en disciplinas como la ciencia política, la sociología, la historia, la economía, entre otras.

La emergencia de una corriente alternativa, que pudiese comprender el proceso político multidimensional en la era de Trump, simboliza un espacio en construcción que tendría que ser abordado por la geopolítica en sus distintas latitudes, en especial, desde una perspectiva crítica en el sur global. Esta última se caracteriza por complejizar las acciones, los discursos y la realidad política, económica, cultural y societal, ejercida históricamente por los Estados Unidos sobre América Latina y el Caribe, Asia, África y la Europa periférica.

En primera medida, esta obra empieza con el artículo de Marco Antonio Gandásegui (hijo), el cual parte de complejizar el "estilo" de la acción política de Trump en un escenario concreto, como lo representa la dinámica electoral nacional en USA. Señala que el triunfo de Trump, dentro del Partido Demócrata y su proyección nacional, responde a la reactivación de "viejos" sentimientos, valores y emociones, tanto negativos como positivos (racismo, xenofobia, segregación, nacionalismos, patriotismos, sueño americano, superioridad estatal, entre otros), encarnados en el imaginario popular y colectivo de los distintos grupos sociales en esa nación, ya que logró hacer eco y manifestarse en el triunfo de los sectores corporativos, empresariales, militares, así como gran parte de la población migrante (legal), dado el apoyo que obtuvo Trump en las urnas.

La reflexión de Gandásegui reconoce que el fortalecimiento de un discurso basado en la superioridad (militar, económica y política) y la apuesta por un régimen de proteccionismo económico fueron algunas de las razones que impulsaron el triunfo de Trump en el escenario político-electoral. Un aspecto de gran interés en esta propuesta radica en el contraste teórico-analítico entre Kissinger, Brzezinski y la perspectiva del sistema-mundo de Wallerstein, enfocada en comprender la interacción del capital en el proceso de la modernización del Estado, a su vez, los cambios en materia de política exterior y el fortalecimiento del poder hegemónico de Trump en la región; una muestra concreta es el análisis de las relaciones sociopolíticas entre los Estados Unidos y el Gobierno panameño. 
En ese tenor, aparece la discusión realizada por el maestro Jaime Preciado, el cual se encarga de teorizar el imaginario democrático de los Estados Unidos, empezando por mencionar la capacidad del poder instituido que se encuentra en la lógica del "totalitarismo invertido" y el fascismo societal. Parte de argumentar la importancia de reconocer la concepción de los poderes fácticos y cómo estos se encargan de politizar las distintas dimensiones del Estado; por ello, categorías de naturaleza sociocultural como la discriminación, el patriarcalismo, el populismo, la soberanía popular, el nacionalismo, el patriotismo y el famoso destino manifiesto, basado en un imaginario del "sueño americano", que constituye el corpus estadounidense.

La discusión de Preciado se identifica como un aporte epistémico en el campo de la geopolítica crítica del sur, al señalar la necesidad de plantear un abordaje descolonizador, encargado de cuestionar la democracia liberal y tanto la dinámica de una sociedad neoliberal como una globalización fundamentada en la desigualdad estructural entre las naciones, Estados, Gobiernos y pueblos en las diferentes regiones del mundo.

Asimismo, la mirada de una descolonización de la geopolítica en el sur está sustentada en analizar experiencias de forma crítica, tal como sucede con la lógica pragmática fundamentada por Trump, caracterizada por el proteccionismo nacionalista, el giro conservador excluyente, racista y clasicista, sin dejar a un lado la posibilidad hipotética de una visión internacional neoconservadora "trumpista".

Lo interesante de esta propuesta radica en la mirada descolonizadora que Preciado construye, partiendo de reconocer los vacíos que se generan en torno al populismo autoritario; la regulaciones ambientales, económicas y monetarias; el fortalecimiento del imaginario racista, xenófobo y clasicista, sin desconocer la manipulación mediática y gubernamental que ejerce Estados Unidos sobre la razón del Estado, la industria militar, los derechos humanos y el decisionismo e inferencia sobre la autonomía/soberanía en las naciones.

Por otro lado, aparece la discusión abordada por José Hernández Martínez sobre el análisis político-electoral de naturaleza coyuntural que se genera producto del triunfo "trumpista" en los Estados Unidos, el cual, considera, no se constituye como un argumento central para comprender la dinámica interna/externa de la sociedad neoliberal en el marco del capitalismo expansionista de esta nación. 
Hernández Martínez cree de gran relevancia reconocer la situación de los Estados Unidos, que vive un liderazgo en declive, producto de la crisis del capitalismo mundial, la lógica de flujos, reflujos y ajustes realizados por los gobiernos de turno (los tiempos no son los mismos de ayer), la disputa por el poder político a cargo de las élites hegemónicas (económicas, académicas, industriales, empresariales, militares, políticas, entre otras). Estas han constituido un orden de conflictividad, desequilibro y restructuración en temas como la seguridad, la política exterior, las relaciones multilaterales y el colonialismo que proyecta el Gobierno norteamericano, con el objetivo de mantener el statu quo sobre las distintas regiones del mundo.

Nos menciona Hernández que el fenómeno "trumpista" emerge producto de la crisis sistémica estadounidense, que no se concentra en la democracia liberal, procedimental y partidista (crisis de la institucionalidad de partidos), sino que se revela en medio de un conjunto ideológico de valores, creencias, acciones y marcos enfocados en refortalecer el pensamiento conservador, totalizador y hegemónico trumpista. Lo anterior, por medio de las instituciones al servicio del capital privado trasnacional, los grupos corporativos y los actores segregacionistas, lo que, en términos del maestro Jaime Preciado, se caracteriza como un "populismo nativista" propio de la incapacidad de los poderes fácticos por mantener un orden hegemónico.

La discusión planteada por Luis Fernando Ayerbe contempla un diseño reflexivo sobre los procesos políticos ejercidos en las últimas décadas por los Estados Unidos, que reflejan la crisis sistémica y societal enfrentada por este gobierno en su famoso proyecto de "destino manifiesto". Ello simboliza las contradicciones casi naturales de administraciones como Bush, Clinton, Obama y Trump, dada la agudización de la crisis institucional, política, armamentista, territorial, energética y gubernamental que proyecta Estados Unidos.

El artículo de Silvina Romano se identifica con el debate en torno a la cuestión ideológica norteamericana y cómo esta ha sido generada bajo la lógica de reproducción, a cargo de los grupos hegemónicos y los medios masivos manifestados en los poderes fácticos. La autora aborda la importancia de reconocer un ambiente caracterizado por el efecto perverso producto de la figura de Trump, que ha fortalecido el imaginario de crisis de derechos humanos, la negación de la otredad y el extermino justificado, producto de la razón estatal. 
Luis Suárez Salazar realiza un análisis cronológico sobre los primeros 155 días de la era "trumpista". Considera la postura del Gobierno frente a países como México, Colombia, Venezuela y Cuba, caracterizados por generar mayor control político institucional, a través de los sectores alineados al poder capitalista, o aquellos identificados por ser grupos "opositores" o "detractores" de los actuales gobiernos. A su vez, menciona el debilitamiento en materia de integración que viene realizando en América Latina, en particular, su postura negativa sobre experiencias de integración como Unasur, Celac, Alba y Mercosur.

Al mismo tiempo, Suárez Salazar aborda el acercamiento estratégico que ha realizado la administración de Trump con los gobiernos de derecha (Argentina, Paraguay y Panamá), dado que representan un escenario enfocado en fortalecer la política exterior y contribuir al control gubernamental en la región. Esta situación despierta diversos análisis en materia de avance, retroceso o estancamiento de los procesos sistémicos por establecer una democracia liberal sumergida en el sistema-mundo capitalista.

En este sentido, el análisis realizado por Ofelia Pérez responde a la discusión sobre los fundamentos encargados de generar una lógica de integrismos/integración en la política estadounidense. La autora considera que la religión se constituye como una práctica sociocultural, la cual genera cohesión y fuerza por establecer un régimen conservador propio de la era "trumpista". Asimismo, menciona que los fundamentalismos fueron factores decisivos en el triunfo de Trump en las elecciones. La razón radica en el fortalecimiento del imaginario interno nacionalista, conservador, populista y xenofóbico que se ha constituido a partir de la fuerza realizada por los sectores neoconservadores/extrema derecha, encargados de mantener un poder hegemónico neoliberal en el exterior, pero al interior una estructura proteccionista nacional.

El aporte de Jorge Rojas Hernández es de suma importancia, dado que analiza los tiempos de crisis globales y transformaciones en las estructuras económicas, políticas, culturales, ambientales, climáticas y territoriales en el mundo, lo que se refleja en la noción de la crisis civilizatoria de nuestros tiempos. El autor contempla la necesidad de debatir la reconfiguración de los órdenes gestados en los últimos tiempos, en los que se observa cómo Estados Unidos ha perdido fuerza en las regiones, y hace uso tanto de los conflictos 
internos como de las guerras para seguir su política internacionalista/intervencionista en materia de la "defensa" de los derechos humanos en el mundo.

Por ello, Rojas Hernández manifiesta que vivimos un momento de compleja transición, en el cual las relaciones entre los gobiernos están mediadas por conflictividades. Aquí toma fuerza la discusión de ir más allá de la lógica electoral y dar paso a las políticas que reproducen el control político, territorial e institucional en gran parte de los gobiernos de América Latina, a través de prácticas como racismo, segregación y xenofobia, que reflejan la dimensión negativa de la cultura estadounidense.

La propuesta central de esta obra radica en analizar la hegemonía y democracia a partir de la era de Trump, ya que se constituye como un referente geopolítico neoconservador. En esa perspectiva, sobresale la importancia de conocer la "nueva política" como una dinámica enfocada en reflexionar sobre las relaciones desiguales entre los mal denominados gobiernos periféricos o desarrollados, dado que responden a un discurso ideológico-colonialista que sigue agudizándose por medio de las formas históricas de dominación ideológica propia de los Estados Unidos.

El análisis de Leandro Morgenfeld se identifica con la visión generada por Trump para los gobiernos de Europa, dado que se nota una profundización negativa, excluyente y nociva de las políticas del nuevo gobierno en materia social, económica, étnica, identitaria, política, cultural, entre otras. La actual dinámica de la era "trumpista" se reconoce como una dimensión del neoliberalismo societal, económico y corporativo, pero, a su vez, como una estructura neoconservadora en materia de derechos sociales, económicos, civiles, relaciones socioculturales y religiosas, migratorias y territoriales que evidencian un retroceso de avanzada en el imaginario "democrático".

Por último, aparece el ensayo de Martha Nélida, a modo de epílogo, el cual explica las elecciones en Estados Unidos y señala que es importante identificar el gobierno de Trump como una estructura político-clientelar, encargada de negar la otredad, establecer una distinción racial y migratoria, sin dejar a un lado el uso del lenguaje violento que genera conflictos entre grupos sociales de dicho país, lo que implica el giro hacia una política y un imaginario neoconservadores en el gobierno trumpista. Aquí se refleja la contradicción entre un gobierno "promotor" de los DDHH y DIH, al mismo tiempo que uno de los principales expulsores de migrantes, enajenadores de 
recursos energéticos e impulsores del intervencionismo sistémico sobre los gobiernos periféricos y no alineados al modus operandi de la colonialidad/ colonialismo del poder estadounidense.

En particular, esta obra intitulada Hegemonía y democracia en disputa. Trump y la geopolítica del neoconservadurismo se constituye como un gran referente o aporte a la geopolítica crítica del sur, es decir, un camino enfocado a descolonizar este campo de estudio que históricamente se encargó de analizar las guerras. En este caso, se configura una apuesta orientada a complejizar las relaciones de los gobiernos, las dinámicas de los Estados y la integración en temas comunes (violencia, conflicto, migración, racismo, xenofobia, exclusión entre otros) que se presentan en América Latina y el Caribe.

\section{PORTADA DEL LIBRO}

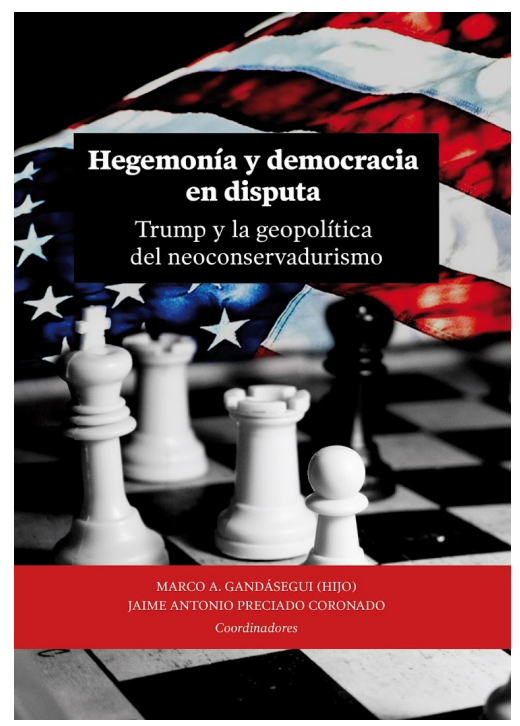

Fuente: Gandásegui, A. y Preciado, J. (2017). Hegemonía y democracia en disputa. Trump y la geopolítica del neoconservadurismo. México: Universidad de Guadalajara. Centro Universitario de Ciencias Sociales. 
